\title{
Anti-PD-L1 Monoclonal Antibody CBT-502
}

National Cancer Institute

\section{Source}

National Cancer Institute. Anti-PD-L1 Monoclonal Antibody CBT-502. NCI Thesaurus. Code C156692.

A humanized immunog lobulin G1 (IgG1) monoclonal antibody directed ag ainst the immunosuppressive lig and programmed cell death-1 (PD-L1; cluster of differentiation 274; CD274), with potential immune checkpoint inhibitory and antineoplastic activities. Upon administration, anti-PD-L1 monoclonal antibody CBT-502 specifically targets and binds to PD-L1, preventing the binding and subsequent activation of its receptor, programmed cell death 1 (PD-1; PDCD1; CD279; programmed death-1). This reverses Tcell inactivation caused by PD-L1/PD-1 signaling, increases T-cell expansion and enhances the cytotoxic T-lymphocyte (CT L)-mediated anti-tumor immune response against PD-L1-expressing tumor cells. PD-L1, a transmembrane protein expressed on activated T-cells, is overexpressed in some cancer types and plays a significant role in immune evasion by tumor cells. 